\title{
JURISPRUDENCIA CONSTITUCIONAL EN MATERIA DE PROTECCIÓN DEL MEDIO AMBIENTE
}

\author{
JORDI JARIA I MANZANO \\ Profesor Serra Húnter de Derecho Constitucional y Ambiental \\ Universitat Rovira i Virgili
}


Sumario: 1. Nuevas historias sobre la difícil convivencia entre la protección del medio ambiente y las competencias estatales en materia de defensa. 1.1. La prohibición autonómica de usos militares en espacios naturales protegidos. 1.2. La prevención de la contaminación en relación con actividades en materia de defensa. 2. Residuos de industrias extractivas y rehabilitación de espacios afectados por actividades mineras: un nuevo episodio de erosión competencial de las comunidades autónomas. 3. Otra serie que continúa: la discusión competencial sobre la fractura hidráulica. 4. La supresión de los incentivos a las energías renovables. 5. Incidencia de las competencias autonómicas en la ordenación del litoral. 6. A vueltas con la política hidráulica.

\section{Nuevas historias sobre la difícil convivencia entre la protección del medio ambiente y las competencias estatales en materia de defensa}

\subsection{La prohibición autonómica de usos militares en espacios naturales protegidos}

Como decía en la crónica anterior, la confluencia de intereses sociales divergentes en la gestión del territorio conlleva que determinadas decisiones tuitivas en este ámbito generen desacuerdos entre actores políticos distintos, para los que un determinado espacio debe cumplir funciones que eventualmente pueden ser incompatibles. La propia complejidad de las competencias que se vierten sobre un mismo espacio y la concurrencia de visiones políticas y sociales distintas, así como de circunscripciones de representatividad de distinta extensión, dan lugar a una particular conflictividad. Uno de los casos paradigmáticos de tal conflictividad es el que deriva de la mutua incompatibilidad entre los usos militares y la protección de ciertos espacios naturales, que ha generado algunas resoluciones del Tribunal Constitucional en los últimos tiempos.

En este caso, se trata de la STC 182/2014, de 6 de noviembre (BOE, núm. 293, de 4 de diciembre de 2014), que ha recaído en relación con el recurso de inconstitucionalidad interpuesto por el presidente del Gobierno contra los incisos 9, 13 y 23 del apartado 2.1.4 y los incisos 27, 29, 30, 31 y 36 del apartado 2.2.4, todos ellos del anejo 2 de la Ley de Castilla-La Mancha 5/2011, de 10 de marzo, de declaración del Parque Natural de la Sierra Norte de Guadalajara. El conflicto reproduce el que resolvía la Sentencia 154/2014, de 25 de septiembre, relativa a la Ley de Castilla-La Mancha 6/2011, de 10 de marzo, de declaración del Parque Natural del Valle de Alcudia y Sierra Madrona.

A juicio del Abogado del Estado, los mencionados preceptos vulneran competencias estatales al establecer la incompatibilidad de determinados usos, aprovechamientos y actividades con la conservación de los diferentes recursos naturales objeto de protección mediante la declaración del parque natural, lo que acaba implicando la prohibición de 
tales usos y actividades. En este caso, las competencias estatales vulneradas serían, a juicio del recurrente, la relativa a las aguas (art. 149.1.22 CE), la relativa a las obras públicas de interés general (art. 149.1.24 CE) y la relativa a defensa (art. 149.1.4 CE), además de referirse también a la consabida competencia en relación con la legislación básica en materia de protección del medio ambiente (art. 149.1.23 CE). Cabe recordar aquí que el contencioso en el caso de la Ley 6/2011 se centraba en las materias de defensa y aprovechamientos hidráulicos, que constituyen, de hecho, el núcleo del presente recurso.

En relación con la primera de las referidas, los incisos 9 y 13 del apartado 2.1 .4 y los incisos 27, 29, 30 y 31 del apartado 2.2.4, del referido anejo 2 de la Ley, declaran como usos, aprovechamientos y actividades incompatibles, y, por lo tanto, prohibidos en el parque natural, las obras de drenaje y desecación, la construcción de presas, canales y trasvases, las centrales hidroeléctricas, la construcción o ampliación de embalses o acequias, los dragados y las nuevas explotaciones de recursos hídricos. Ello, a juicio del abogado del Estado, se proyecta también sobre la competencia del artículo 149.1.24 en la medida en que incide sobre las obras hidráulicas relacionadas con lo anterior.

Por otro lado, en relación con las competencias estatales en materia de defensa, los incisos 23 del apartado 2.1.4 y 36 del apartado 2.2.4 del anejo 2 incluyen, entre los usos, aprovechamientos y actividades incompatibles, las maniobras y los ejercicios militares, con la única excepción de los que estén destinados a situaciones de emergencias por incendios forestales, salvamento o inclemencias del tiempo (fuera de la zona de protección especial). En este sentido, es de recordar que el Decreto 191/2002, de 15 de febrero, declara "zona de interés para la defensa nacional" la superficie cuyas coordenadas se definen en dicha norma y que coinciden parcialmente con los límites de la zona del Parque Natural de la Sierra Norte de Guadalajara y con la zona de protección especial (Pico del Lobo-Hayedo de Tejera Negra). Finalmente, el Abogado del Estado se refiere también al artículo 3.1 de la Ley 5/2011, considerando que contradice la legislación básica estatal contenida en la Ley 42/2007, de 13 de diciembre, del patrimonio natural y de la biodiversidad, al atribuir carácter vinculante, que no determinante, a los planes de usos del espacio natural protegido. Aunque bien es verdad que tal artículo no forma parte de los preceptos impugnados.

Como en el caso de la ya referida STC 154/2014, de 25 de septiembre, en este caso el Tribunal Constitucional considera que las competencias estatales en materia de aguas no 
se ven invadidas y, por ese mismo motivo, dada la conexión que establece el propio recurrente, tampoco lo serían las relativas a las obras públicas de interés general. Sin embargo, como en la anterior ocasión, considera que, efectivamente, se han conculcado las competencias estatales en materia de defensa. Así, el Tribunal se remite de nuevo a la doctrina establecida en la STC 82/2012, de 18 de abril, que también fue comentada en su momento en estas crónicas ${ }^{1}$. De acuerdo con ello, en materia de defensa nacional, el ejercicio por el Estado de su competencia impide de raíz toda posibilidad de una acción autonómica de signo contrario (FJ 2. ${ }^{\circ}$ f). Sin embargo, como subrayaba la referida STC 154/2014, de 25 de septiembre, "la decisión que adopte el Estado sobre las actividades y usos militares que se vayan a realizar sobre el espacio protegido estará obligada a ponderar los intereses públicos concurrentes y, en especial, los intereses ecológicos y medioambientales que haya tenido en cuenta la Comunidad Autónoma al ejercer su legítima competencia sobre espacios naturales protegidos, y así podrán instarlo las Comunidades Autónomas mediante el ejercicio de las acciones que les competen" (FJ 2. ${ }^{\mathrm{o}} \mathrm{f}$.

En relación con ello, de acuerdo con la opinión del Alto Tribunal, la "ponderación que hemos reclamado puede encontrar un cauce adecuado en las previsiones del art. 2.3 del Real Decreto 191/2002, que exige autorización del Ministerio de Defensa para la 'determinación de la compatibilidad de los fines de la defensa nacional de cualquier regulación, ordenación o actuación administrativa que pueda incidir en la utilización militar de la instalación o en el eficaz funcionamiento de los medios de control de tráfico aéreo en ella localizados"” (FJ 2. ${ }^{\circ}$ f).

\subsection{La prevención de la contaminación en relación con actividades en materia de defensa}

La Sentencia 192/2014, de 20 de noviembre (BOE, núm. 308, de 22 de diciembre de 2014), resuelve el recurso de inconstitucionalidad promovido por el Presidente del Gobierno contra el epígrafe 75.22, "Defensa”, del anexo II de la Ley de la Comunidad Autónoma del País Vasco 1/2005, de 4 de febrero, para la prevención y corrección de la contaminación del suelo. Dicho recurso fue presentado fundamentándose en un doble

\footnotetext{
${ }^{1}$ Vid. JARIA I MANZANO, Jordi, "Jurisprudencia constitucional en materia de protección del medio ambiente”, Revista Catalana de Dret Ambiental, vol. III, núm. 2, $2012<\mathrm{http}$ ://rcda.cedat.cat/>, p. $5 \mathrm{ss}$.
} 
orden de consideraciones. Por una parte, habría, a juicio del recurrente, una violación de la legislación básica en materia de residuos, que excluye de su ámbito de aplicación "los suelos de titularidad pública en los que se ubiquen instalaciones militares o en los que se desarrollen actividades militares" (anexo II del Real Decreto 9/2005, de 14 de enero, por el que se establece la relación de actividades potencialmente contaminantes del suelo y los criterios y estándares para la declaración de suelos contaminados, de acuerdo con la remisión a las "leyes reguladoras de la Defensa Nacional" — disposición adicional cuarta de la Ley 10/1998, de 21 de abril, de residuos-).

Por otra, aunque en cierto modo de manera confluyente, se alude a una invasión de las competencias estatales en materia de defensa consagradas en el artículo 149.1.4 CE. De alguna manera, la exclusión, en la legislación básica en materia de residuos, de estos suelos en particular llevaría a la ubicación de su régimen jurídico, en relación con su eventual contaminación, a su incorporación al título competencial de defensa. De acuerdo con la argumentación de la parte recurrente, el sentido de la normativa básica aludida es justamente el de sustraer la actividad de defensa del régimen general relativo a los suelos contaminados, de modo que se establece un régimen especial para dichas actividades de defensa, incluso en relación con este aspecto, sin discutir si tales actividades son potencialmente contaminantes.

Por su parte, la parte recurrida señala que la remisión a las leyes promulgadas en el ámbito de la defensa contenida en la citada disposición adicional cuarta de la Ley 10/1998 no excluye la materia de suelos contaminados de la protección del medio ambiente, lo que da, en consecuencia, entrada a la normativa autonómica tanto como desarrollo legislativo como en cuanto normas adicionales de protección (art. 148.9 CE). La exclusión de los suelos en los que se desarrollan actividades militares de la regulación de los residuos se produce, en realidad, en el Real Decreto 9/2005.

Considera el Letrado del Parlamento Vasco que ello constituye una norma que excede las atribuciones competenciales del Estado por motivos formales en la medida en que se trata de legislación básica incluida ilegítimamente en un reglamento y, por lo tanto, a su juicio, sin cumplir con las limitaciones formales a las que debería haberse atenido estar contenido en una norma con rango de ley-. También se defiende por parte de la Comunidad Autónoma que no existe vulneración de las competencias estatales en materia de defensa en la medida en que coinciden sobre el espacio intereses diversos, 
sin que pueda entenderse que el ejercicio de la competencia autonómica en materia de protección del medio ambiente impida el ejercicio de la competencia estatal.

Como acostumbra a suceder, la Sentencia en relación con el conflicto planteado recae tras casi una década desde la impugnación, de manera que la legislación básica aplicable ha cambiado con la entrada en vigor de la Ley 22/2011, de 28 de julio, de residuos y suelos contaminados, que derogó la anterior Ley 10/1998. Sin embargo, el Tribunal Constitucional subraya que, en este aspecto, el régimen jurídico contenido en la Ley en vigor es virtualmente el mismo y que, por otro lado, no ha comportado la derogación del Real Decreto 9/2005. En este sentido, el conflicto se mantiene en los mismos términos en que fue formulado originalmente.

A partir de lo establecido en las comentadas SSTC 182/2014, de 6 de noviembre, y 154/2014, de 25 de septiembre, el Tribunal señala que las reglas básicas estatales pueden ser exceptuadas o reguladas en términos distintos por la propia legislación del Estado en los ámbitos sectoriales concretos en los que este ejerce sus competencias (FJ 3. ${ }^{\circ}$ ). Fija, por lo tanto, el punto de partida en los términos en los que lo hace el Abogado del Estado, de modo que, en caso de que se hubiera producido correcta y explícitamente la separación de la regulación de los suelos contaminados en relación con las instalaciones militares en la legislación básica estatal, cabría entender que tal regulación se incorporaría a la competencia estatal de defensa y excluiría la intervención autonómica. Así las cosas, el Tribunal Constitucional concluye lo siguiente:

La inclusión del epígrafe 75.22, referido a la actividad o a las instalaciones de "Defensa", en la relación establecida en el anexo II — que recoge las que potencialmente son susceptibles de generar contaminación del suelo-, sin establecer ningún tipo de acotación o de modulación en relación con las obligaciones que se establecen supone una interferencia y una perturbación del ejercicio de las competencias estatales. Así, la Comunidad Autónoma Vasca no puede sujetar los suelos afectos al uso militar al régimen general y completo de control establecido por la Ley autonómica pues la eventual actuación del órgano autónomo vasco previsto en la Ley para la supervisión de todas las medidas de protección y reparación de los suelos y actividades potencialmente contaminantes $-\mathrm{y}$ que incluye, entre otras, la posibilidad de que se ordene al titular de la actividad o instalación la adopción de medidas, el sometimiento a autorización autonómica de la ampliación de la actividad o ciertas potestades de inspección y vigilancia, todas ellas acompañadas de un régimen sancionador para quienes incumplan las prescripciones impuestas-, necesariamente incide en el ámbito propio del 
funcionamiento de las Fuerzas Armadas, que constituye uno de los elementos esenciales del ejercicio de la competencia exclusiva del Estado en materia de defensa [FJ 5. ${ }^{\circ}$.

De ello deriva, en definitiva, la inconstitucionalidad por incompetencia, en la medida en que incide en el título estatal en materia de defensa, de la norma autonómica. El Tribunal no dedica, sin embargo, ninguna consideración a la impugnación del carácter de legislación básica del Real Decreto 9/2005, dada la objeción de la representación del Parlamento Vasco en relación con este particular. Según el Tribunal Constitucional, "la Ley 10/1998, de 21 de abril, como el Real Decreto 9/2005, de 14 de enero, se fundamentan en el título competencial estatal referido a la legislación básica sobre protección del medio ambiente, reconocido en el artículo 149.1.23 de la Constitución", mientras que "las concretas previsiones que suponen el establecimiento de una excepción al régimen de aplicación de las normas básicas sobre medio ambiente en un ámbito sectorial concreto se fundan en la competencia que tiene atribuida el Estado ex art. 149.1.4 CE".

De este modo, parece sugerir que la decisión estatal de exceptuar de la aplicación de las normas básicas un determinado ámbito en el que tiene una competencia no es una decisión dictada al amparo de la propia legislación básica, sino del ámbito competencial concreto. Ello es un paso más en la doctrina sentada en su día en la STC 13/1998, de 22 de enero, cuya conclusión, en este estadio, es que el Estado puede hacer excepción de sí mismo en relación con la normativa aplicable a la protección del medio ambiente, siempre que lo considere oportuno, ya que sus competencias sectoriales incluyen la propia vertiente ambiental de estas, mientras que no sucede lo mismo en el ámbito autonómico, donde tal normativa tiene la consideración de básica.

Curiosa legislación básica, por cierto, aquella que solo es vinculante para una parte de los actores públicos, no ofreciendo más que parcialmente, por lo tanto, el umbral mínimo de protección que era su razón de ser. A mi juicio, esta deriva de la jurisprudencia constitucional, basada en una mala comprensión de su propia concepción de la legislación básica en este punto y una sobreprotección del ejercicio de las competencias estatales en perjuicio de la protección del medio ambiente cuando esta está encomendada a las comunidades autónomas, es inasumible, más cuando el Tribunal Constitucional es asimismo reticente a utilizar el artículo $45 \mathrm{CE}$ como parámetro de constitucionalidad de la legislación estatal. De acuerdo con la interpretación del Alto Tribunal, en definitiva, las instituciones del Estado acaban teniendo una disponibilidad 
absoluta en relación con el bien jurídico, que queda huérfano de defensa en relación con su actividad. La tendencia antiautonomista del Tribunal, reforzada en los últimos años, se une aquí a una carencia de sensibilidad bastante preocupante en relación con la protección del medio ambiente.

\section{Residuos de industrias extractivas y rehabilitación de espacios afectados por} actividades mineras: un nuevo episodio de erosión competencial de las comunidades autónomas

La Sentencia 45/2015, de 5 de marzo (BOE, núm. 85, de 9 de abril de 2015), se pronuncia sobre el conflicto positivo de competencia núm. 7869-2009, promovido por la Xunta de Galicia en relación con el Real Decreto 975/2009, de 12 de junio, sobre gestión de los residuos de las industrias extractivas y de protección y rehabilitación del espacio afectado por actividades mineras. Dicha norma pretendía incorporar al Derecho español la Directiva 2006/21/CE, y se refiere a la gestión de los residuos que derivan de las industrias extractivas, así como a la protección y rehabilitación de las zonas afectadas por estas actividades. El Estado otorgó carácter básico a esta regulación apoyándose en sus competencias en materia de medio ambiente (art. 149.1.23 CE), en general, y de minas (art. 149.1.25 CE), en relación con los artículos 2, 4, 5, 7, 8, 9, 10, $11,13,14,15,36,44,45 \mathrm{y} 46$, disposiciones adicionales tercera y cuarta y disposiciones transitorias segunda y tercera del Real Decreto impugnado. Finalmente, el Estado se ampara en sus competencias en materia de seguros (art. 149.1.11 CE) con relación al título II de la disposición impugnada.

Pues bien, la representación procesal de la Xunta de Galicia considera que el Estado ha hecho un uso exorbitante de sus competencias al atribuir carácter básico a tal disposición, sin que, como es sabido, el Derecho de la Unión Europea pueda justificar la asunción por parte del Estado de competencias de las que no dispone. En este sentido, la parte recurrente subraya que la norma impugnada carece del rango legal exigible, a su juicio, con carácter general a toda legislación básica y desborda, además, el ámbito material de lo básico. Subsidiariamente, la Xunta de Galicia pide la declaración de inconstitucionalidad de determinados preceptos de la norma impugnada en la medida en que, nuevamente, excederían el ámbito de lo básico e impedirían el desarrollo legislativo por parte de la Comunidad Autónoma. 
Por su parte, el Abogado del Estado se ampara, desde el punto de vista formal, en las abundantes excepciones que el Tribunal Constitucional ha permitido en cuanto al rango legal de lo básico. Por otro lado, en relación con la dimensión material de lo básico, el Abogado del Estado considera que la norma impugnada deja espacio para el desarrollo autonómico, configurándose como una norma de mínimos que las normas autonómicas pueden mejorar - mezclando, de paso, los conceptos de desarrollo legislativo y normas adicionales de protección-. Formulado en estos términos, el conflicto se refiere, pues, al alcance de los límites materiales y formales de lo básico, fundamentalmente en materia de protección del medio ambiente. Este es el punto de partida que adopta el Tribunal Constitucional, que considera que "[a] la vista del sentido de los apartados 23 y 25 del artículo 149.1 CE y del carácter y finalidad de la regulación impugnada, no cabe duda de que el título competencial específico y prevalente en el que se enmarca la presente controversia es 'legislación básica sobre protección del medio ambiente, sin perjuicio de las facultades de las Comunidades Autónomas de establecer normas adicionales de protección' (art. 149.1.23 CE). El análisis singularizado de los preceptos impugnados, también los que la disposición final segunda declara básicos conforme a otros títulos competenciales, confirma esta conclusión con sólo alguna excepción" (FJ $\left.3 .^{\circ}\right)$.

A partir de aquí, el Alto Tribunal se concentra en el análisis de la objeción en cuanto al rango de la norma impugnada, para insistir en su generoso punto de vista en relación con la idoneidad del reglamento. Así, considera lo siguiente:

Ciertamente, la norma de rango legal es el instrumento idóneo para establecer bases porque a través de ella se alcanza, "con las garantías inherentes al procedimiento legislativo, una determinación cierta y estable de los ámbitos respectivos de ordenación de las materias en las que concurren y se articulan las competencias básicas estatales y las legislativas y reglamentarias autonómicas" (STC 69/1988, de 19 de abril, FJ 5). Se trata, no obstante, de una exigencia no absoluta; en determinadas circunstancias el Gobierno de la Nación puede hacer uso de su potestad reglamentaria para regular aspectos básicos de una materia. Una de las circunstancias que ha justificado históricamente la fijación reglamentaria de bases fue la necesidad "impuesta por una situación de transición" de "adecuar la legislación preconstitucional a situaciones nuevas derivadas del orden constitucional" (STC 69/1988, FJ 5). Junto a ella, hay las que ha ido perfilando la doctrina constitucional, desvinculadas ya de aquella situación transitoria y asociadas a las características de determinados sectores: "en algunas materias ciertas decisiones y 
actuaciones de tipo coyuntural, que tienen como objeto la regulación inmediata de materias concretas, pueden tener sin duda un carácter básico, y, en consecuencia, el Gobierno podrá hacer uso de su potestad reglamentaria para regular por Real Decreto, y, de modo complementario, algunos de esos aspectos particulares o concretos de la materia básica" (STC 77/1985, de 27 de junio, FJ 16). En varios sectores, como el educativo, el Tribunal ha afirmado específicamente que la regulación reglamentaria de carácter básico "resultaría acorde con los preceptos constitucionales si, primeramente, resultara de una habilitación legal, y, en segundo lugar, si su rango reglamentario viniera justificado por tratarse de materias cuya naturaleza exigiera un tratamiento para el que las normas legales resultaran inadecuadas por sus mismas características" (por todas, SSTC 77/1985, FJ 16; 184/2012, FJ 3). Respecto de la materia que aquí interesa, este Tribunal ha reputado básicas regulaciones reglamentarias por parecidas razones: "el carácter básico en su perspectiva formal del Real Decreto impugnado puede deducirse con facilidad de su estructura y contenido, ya que su articulado enlaza con la expresa previsión de la Ley y desarrolla su regulación en lo relativo a la organización y funcionamiento de las comisiones mixtas de gestión y de los patronatos de los parques nacionales" (STC 32/2006, de 1 de febrero, FJ 5) [FJ 4. ${ }^{\circ}$ ].

Como era previsible, el Alto Tribunal concluye que, en el caso que nos ocupa, "hay que entender que el Real Decreto controvertido se ajusta a la doctrina constitucional sobre la dimensión formal de las bases". No hace falta decir que el juez de la constitucionalidad no se detiene a analizar hasta qué punto existe una necesidad concreta para justificar la disposición impugnada, a fin de garantizar la regulación básica de la materia, siendo suficiente, al parecer, la remisión de la ley al reglamento y una afirmación incidental sobre el carácter "marcadamente" técnico de la materia para amparar la intervención estatal. En este sentido, el Tribunal Constitucional continúa abonando una concepción elástica de lo básico que tiende a erosionar el margen de autogobierno de las comunidades autónomas, en el marco de un debate procesal que, por otro lado, tiende a desconocer los efectos del principio dispositivo y de las diferencias (potenciales o reales) entre los acervos competenciales de las diferentes comunidades autónomas - lo que, en particular con el juego de la cláusula de cierre del artículo 149.3 CE, puede implicar que ciertas normas estatales no básicas sean constitucionales y vigentes para ciertas partes del territorio en función de las competencias asumidas por las distintas comunidades autónomas-. 
$\mathrm{Si}$, desde el punto de vista formal, la norma no plantea, como se ha visto, ningún problema al Tribunal Constitucional, en cuanto a los aspectos materiales, el Tribunal Constitucional da un paso más allá en el apoderamiento de las instituciones centrales del Estado, avanzando en la línea apuntada por las sentencias 69/2013, de 14 de marzo, y 138/2013, de 6 de junio. Ambas sentencias fueron comentadas en sendas crónicas publicadas anteriormente en la $\mathrm{RCDA}^{2}$. En particular, en relación con la segunda de las sentencias aludidas, subrayé en su momento los esfuerzos del Tribunal Constitucional para "construir una posición razonable y sensible con la problemática planteada", aunque también apuntaba a los riesgos que tal posición planteaba desde el punto de vista del crecimiento de las competencias del Estado. Creo que tales temores se hacen efectivos en la Sentencia ahora comentada, en que, tomando pie en las resoluciones citadas, el Tribunal Constitucional afirma:

Por lo mismo, "de acuerdo con la tendencia general actual", corresponde al Estado imponer el "encuadramiento de una política global en materia de medio ambiente", teniendo en cuenta el alcance no ya nacional, sino internacional que tiene la regulación de esta materia, así como la exigencia de la "indispensable solidaridad colectiva" a que se refiere el artículo 45.2 CE. De ahí también que la intervención estatal pueda ser "singularmente intensa", que la "piedra de toque" para calificar de básica la norma medioambiental sea más su "finalidad tuitiva" que su carácter genérico o detallado, abstracto o concreto. El deber del legislador básico estatal de dejar un margen a la normativa autonómica será "menor que en otros ámbitos", aunque no pueda llegar "a tal grado de detalle que no permita desarrollo legislativo alguno de las Comunidades Autónomas con competencias en materia de medio ambiente, vaciándolas así de contenido".

Por otra parte, la STC 138/2013, de 6 de junio, FJ 4, al resolver el recurso interpuesto por el Gobierno de la Comunidad de Madrid contra esa misma Ley, ha aislado una relevante línea de la política medioambiental nacional, europea e internacional que es preciso recordar aquí; habrá pues de tenerse en cuenta a la hora de examinar las diversas impugnaciones. En "el marco del Convenio de Aarhus de 1998 y de la legislación comunitaria, la Ley 27/2006, de 18 de julio, establece el derecho de todos a acceder 'a la

\footnotetext{
${ }^{2}$ Vid. JARIA I MANZANO, Jordi, “Jurisprudencia constitucional en materia de protección del medio ambiente”, Revista Catalana de Dret Ambiental, vol. IV, núm. 1, $2013<\mathrm{http}: / /$ rcda.cedat.cat/>, p. 63 y ss., en relación con la primera; y JARIA I MANZANO, Jordi, "Jurisprudencia constitucional en materia de protección del medio ambiente", Revista Catalana de Dret Ambiental, vol. IV, núm. 2, 2013 $<$ http://rcda.cedat.cat/>, p. 15 y ss., en relación con la segunda.

${ }^{3}$ Vid. JARIA I MANZANO, “Jurisprudencia constitucional...”, cit. (2013b), p. 18.
} 
información ambiental que obre en poder de las autoridades públicas o en el de otros sujetos que la posean en su nombre' [art. 1.1 a)], junto a la obligación positiva de las autoridades públicas de difundirla amplia y sistemáticamente (art. 6.1: 'las autoridades públicas adoptarán las medidas oportunas para asegurar la paulatina difusión de la información ambiental y su puesta a disposición del público de la manera más amplia y sistemática posible'). Estas previsiones se concretan en la elaboración y publicación de informes y evaluaciones (arts. 7 y 9), entre otros instrumentos. Se trata de que los ciudadanos puedan contribuir eficazmente a la protección del medio ambiente, para lo cual resulta fundamental la transparencia, sin que las Administraciones públicas puedan dejar de proporcionar o difundir información ambiental escudándose en que se refiere a asuntos que no son de su competencia”.

E1 Real Decreto controvertido se inserta en esta política medioambiental, desarrollando dos pilares del Convenio de Aarhus: el acceso público a informaciones medioambientales y la participación ciudadana en las decisiones con repercusión medioambiental. Incluye mecanismos específicos que, al igual que los examinados por aquella Sentencia, expresan "la apuesta del legislador básico (adoptada, por lo demás, dentro del contexto europeo e internacional) por una concreta política medioambiental, que es la que confía en la iniciativa de los propios ciudadanos para luchar contra la degradación del medio y de la biodiversidad" (STC 138/2013, FJ 4). Ello resulta de la propia exposición de motivos del Real Decreto 975/2009, que se refiere a las dimensiones "informativa” y "participativa" del citado Convenio: "se ha garantizado que, de acuerdo con la Convención de las Naciones Unidas sobre el acceso a la información, la participación pública en la toma de decisiones y el acceso a la justicia en materia de medio ambiente, de 25 de junio de 1998 (Convención de Aarhus), el público sea informado de toda solicitud de autorización de plan de restauración que incluye el plan de gestión de residuos y que el público interesado sea consultado previamente a la concesión de una autorización del plan de restauración". En relación específicamente con la dimensión "informativa", destaca también la previsión de "un inventario de las instalaciones de residuos mineros clausuradas, incluidas las instalaciones abandonadas, situadas en territorio español" [FJ 5..$^{\circ}$.

A partir de esta posición, el Tribunal Constitucional desestima una por una las pretensiones de la parte recurrente, como era previsible atendiendo al razonamiento precitado. En este sentido, la sensibilidad en relación con la protección del medio ambiente, que habíamos subrayado, en particular, al comentar la STC 138/2013, de 6 de junio, parece que era más bien sensibilidad hacia las competencias estatales. Así, si ponemos en conexión lo que dice el Tribunal Constitucional en la sentencia aquí 
analizada con su argumentación en la comentada en el epígrafe anterior - la STC 192/2014, de 20 de noviembre-, resulta claro que la sensibilidad hacia el medio ambiente del Alto Tribunal acaba dependiendo de si tiene consecuencias reductivas o amplificadoras de las competencias estatales, lo que, evidentemente, convierte al Tribunal Constitucional en un actor bastante poco fiable desde el punto de vista de la protección del bien jurídico, además de poco ecuánime desde la perspectiva de los contenciosos entre los diversos poderes del Estado.

\section{Otra serie que continúa: la discusión competencial sobre la fractura hidráulica}

En la crónica anterior me refería a las primeras decisiones que había suscitado la legislación autonómica prohibitiva de la llamada fractura hidráulica o fracking. Se trataba de las SSTC 106/2014, de 24 de junio, y 134/2014, de 22 de julio, que concluían con un pronunciamiento sobre la extralimitación competencial de la ley autonómica respectivamente, la Ley del Parlamento de Cantabria 1/2013, de 15 de abril, y la Ley del Parlamento de La Rioja 7/2013, de 21 de junio-, considerando que "[1]a prohibición de la técnica del fracking [...] vulnera[ba] la competencia estatal ex art. 149.1.13 y $25 \mathrm{CE}$, al excluir la eficacia en el territorio de Cantabria de la legislación básica que se dicta al amparo de los referidos títulos competenciales" (STC 106/2014, FJ 8. ${ }^{\circ}{ }^{4}$. En esta ocasión, debo referirme a la siguiente sentencia dictada por el Tribunal Constitucional en relación con las prohibiciones autonómicas sobre el fracking, cuyo contenido, obviamente, viene marcado por el pronunciamiento anterior al que acabo de aludir.

Así, en el período analizado en esta crónica ha recaído la Sentencia 208/2014, de 15 de diciembre (BOE, núm. 17, de 20 de enero de 2015), que resolvía el recurso de inconstitucionalidad promovido por el Presidente del Gobierno en relación con los artículos 1, 2 y 3, la disposición transitoria única y la disposición final única de la Ley Foral 30/2013, de 15 de octubre, del Parlamento de Navarra, por la que se prohíbe en el territorio de la Comunidad Foral de Navarra el uso de la fractura hidráulica como técnica de investigación y extracción de gas no convencional. Como era de prever, el Tribunal Constitucional ha reiterado la jurisprudencia sentada en los dos pronunciamientos anteriores para concluir, nuevamente, que la Comunidad Foral se

\footnotetext{
${ }^{4}$ Vid., además de la crónica contenida en el número anterior de la RCDA, el trabajo de SANTAMARÍA ARINAS, René Javier, "Las claves jurídicas del debate sobre el fracking", Revista Catalana de Dret Ambiental, vol. V, núm. 1, $2014<$ http://rcda.cedat.cat/>.
} 
había extralimitado en sus competencias. Así, según el Tribunal Constitucional, "[n]o obsta a la aplicación de la citada doctrina, los argumentos que opone el escrito de alegaciones del Letrado del Parlamento de Navarra. Ante todo, no se aducen peculiaridades en las normas ahora cuestionadas respecto de las que ya enjuiciaron las dos Sentencias que cita, ni se plantean temas que no hubieran sido objeto de debate entonces" (FJ 3. $\left.{ }^{\circ}\right)$.

Nos remitimos al voto particular formulado en las SSTC 106/2014 y 134/2014, señalando de nuevo lo subrayado en la crónica anterior, a saber, que el Tribunal Constitucional, nuevamente, "no pondera debidamente la incidencia de los riesgos del fracking en un interés de la máxima relevancia constitucional como es la protección de la salud humana". Teniendo en cuenta otras resoluciones comentadas en esta crónica, debo apuntar, nuevamente, la existencia de una diferente vara de medir en relación con los intereses ambientales en función de si son sostenidos por una normativa estatal o una normativa autonómica, lo que la jurisprudencia sobre el fracking pone de manifiesto de manera dramática, sumándose a otras resoluciones del período que analiza esta crónica para ofrecer un cuadro ciertamente desolador en cuanto a la actividad del Tribunal Constitucional en este ámbito.

\section{La supresión de los incentivos a las energías renovables}

El Real Decreto-ley 1/2012, de 27 de enero, por el que se procede a la suspensión de los procedimientos de preasignación de retribución y a la supresión de los incentivos económicos para nuevas instalaciones de producción de energía eléctrica a partir de cogeneración, fuentes de energía renovables y residuos, ha supuesto un vuelco en la estrategia energética de España en la medida en que se ha pasado de un sistema enfocado hacia el fomento de las energías renovables a una política energética que las desincentiva de modo explícito. Más allá de las consideraciones que puedan hacerse en relación con la falta de visión política de la medida, así como la imagen deplorable que genera la inexistencia de una estrategia energética y la inadecuación del vuelco político en esta materia a un mínimo horizonte de sostenibilidad, desde el punto de vista jurídico se plantean, dadas las inversiones realizadas de acuerdo con el modelo anterior, cuestiones de enjundia en relación con la seguridad jurídica. 
La Sentencia 48/2015, de 5 de marzo ( $\mathrm{BOE}_{2}$ núm. 85, de 9 de abril de 2015), ha tenido que afrontar esta cuestión para resolver el recurso de inconstitucionalidad interpuesto por la Xunta de Galicia contra el citado Decreto-ley 1/2012. El ejecutivo gallego recurre no por motivos competenciales, sino sustantivos, aduciendo la inexistencia del presupuesto habilitante que contempla el artículo $86 \mathrm{CE}$ para acudir a la regulación mediante decreto-ley de una materia, así como la lesión de los principios de seguridad jurídica y confianza legítima que se contienen en el artículo 9.3 $\mathrm{CE}$. En cuanto a la primera cuestión, la impugnación se centra en la falta de justificación de la extraordinaria y urgente necesidad en relación con la energía eólica, así como en el hecho de que el déficit tarifario que justifica la medida no era un hecho nuevo que exigiera una respuesta urgente.

Por otro lado, la Xunta de Galicia argumenta, en relación con la seguridad jurídica, que la previsibilidad del Derecho por parte de los ciudadanos queda conculcada en la medida en que el Decreto-ley 1/2012 deja en la indefinición el régimen económico de los incentivos a las energías renovables por un tiempo indefinido. Ello, como se ha apuntado, afecta a las decisiones de inversión en el sector, pero, además, en opinión de la Xunta de Galicia, impide la realización de cualquier planificación energética por su parte, en particular en relación con medidas de transición energética destinadas a aumentar la participación de las renovables en el mix energético final.

La representación del Gobierno del Estado, por su parte, considera que la medida está suficientemente justificada en relación con los presupuestos habilitantes del decreto-ley en la medida en que, en su opinión, el déficit tarifario se había disparado por las medidas tomadas en 2008 y 2009. Por lo demás, en relación con la seguridad jurídica, el Abogado del Estado aduce que la norma impugnada no presenta dudas ni oscuridades en relación con sus destinatarios, su objeto o sus consecuencias, de modo que se produciría "una perfecta predeterminación de todos los elementos nucleares de la norma".

Pues bien, el Tribunal Constitucional se pronuncia sobre el contencioso planteado, aunque señala, de entrada, que las modificaciones recientes del régimen jurídico del sector eléctrico han supuesto una derogación virtual de la norma discutida. En este sentido, el Tribunal Constitucional hace notar lo siguiente:

Aunque ninguna de las disposiciones citadas, ni siquiera la nueva Ley del sector eléctrico, deroga expresamente el Real Decreto-ley 1/2012, por lo que no se puede 
descartar en este inicial análisis la eventual ultraactividad de algunas de las disposiciones del mismo, la STC 183/2014, de 6 de noviembre, con fundamento en la anterior STC 96/2014, de 12 de junio, vino a establecer que el registro de preasignación de retribuciones fue suprimido por el Real Decreto-ley 9/2013, con la salvedad de su aplicación transitoria en tanto en cuanto se aprobara un nuevo régimen jurídico y económico de la actividad de producción a partir de fuentes de energía renovables, cogeneración y residuos con régimen económico primado. Es este régimen transitorio al que pone fin la Ley 24/2013, del sector eléctrico, desarrollada por el Real Decreto 413/2014, de 6 de junio, por el que se regula la actividad de producción de energía eléctrica a partir de fuentes de energía renovables, cogeneración y residuos, estableciendo el nuevo modelo de retribución. Con arreglo a lo anterior, la STC 183/2014 manifiesta que el panorama normativo descrito permite concluir que la norma recurrida, en tanto en cuanto hace referencia a un régimen económico primado que ya no se encuentra vigente, así como a la inscripción en un registro administrativo en su momento suprimido, no se encuentra materialmente en vigor, pese a no haber sido derogada formalmente, lo que consiente afirmar que las quejas que se imputaban a este precepto en relación con la vulneración del artículo 9.3 CE han desaparecido sobrevenidamente. En el caso que nos ocupa, la aplicación de la doctrina transcrita obliga a alcanzar idéntica conclusión, estimando que la supresión del registro administrativo, cuya actividad suspende el Real Decreto-ley 1/2012, objeto del presente recurso de inconstitucionalidad, en los términos descritos, conduce a entender que las quejas asociadas al mismo, en relación con la vulneración del artículo 9.3 CE han decaído, desapareciendo sobrevenidamente el objeto del recurso en este punto [FJ 2. $\left.{ }^{\circ}\right]$.

Sin embargo, a juicio del Tribunal, ello no impide

[...] "controlar si el ejercicio de la potestad reconocida al Gobierno por el artículo 86.1 CE se realizó siguiendo los requisitos establecidos en dicho precepto constitucional, pues al hacerlo se trata de velar por el recto ejercicio de la potestad de dictar Decretos-leyes, dentro del marco constitucional, decidiendo la validez o invalidez de las normas impugnadas sin atender a su vigencia o derogación en el momento en que se pronuncia el fallo" (STC 31/2011, de 17 de marzo, FJ 2). Por lo tanto y al menos, la cuestión del ajuste del Real Decreto-ley impugnado a las previsiones del artículo $86 \mathrm{CE}$ puede ser, sin ningún género de dudas, afrontada.

Con ello, el pronunciamiento del juez de la constitucionalidad se concentra en la existencia o no del supuesto habilitante del Decreto-ley, para lo que parte de su más que generosa (para con el ejecutivo) interpretación del artículo 86.1 CE. Subrayando la 
importancia de la documentación preparatoria de la norma en relación con la necesidad de atajar el déficit tarifario, el Tribunal Constitucional considera que "con la motivación aportada en la exposición de motivos de la norma, en el debate de convalidación del Decreto-ley, y en la memoria de impacto normativo del Real Decreto-ley, debe darse por satisfecho el requisito de que se hayan explicado las razones de extraordinaria y urgente necesidad que han motivado la suspensión, mediante Real Decreto-ley, del sistema de asignación de incentivos económicos para las instalaciones de producción eléctrica de régimen especial, así como de inscripción de las mismas en el registro de pre-asignación de retribución" (FJ 5. ${ }^{\circ}$ ).

A partir de ahí, el Tribunal analiza si la medida adoptada conecta con la situación de extraordinaria y urgente necesidad que da por establecida. En relación con ello, señala que "el propósito de la norma es evitar el incremento del gasto dedicado a la financiación del sistema primado, derivado de la incorporación de nuevas instalaciones a dicho sistema, para, a partir de ahí, propiciar la reducción del déficit estructural del sector eléctrico. Esto es, el Real Decreto-ley minimiza el riesgo de eventuales desviaciones al alza del déficit, lo que, como dijimos en la STC 183/2014, constituye una situación susceptible de ser abordada mediante la legislación de urgencia, constatándose una evidente conexión entre la situación de extraordinaria y urgente necesidad y las medidas adoptadas para hacerle frente" (FJ 6. ${ }^{\circ}$ ). En este sentido, es cierto que la adopción de tal medida responde, en cierto modo, a criterios de oportunidad política en relación con las medidas que, efectivamente, se tomen para atajar el déficit tarifario, de modo que se explica la prudencia del Tribunal respecto a la adecuación de la medida, obviando el pronunciamiento en relación con una eventual violación de la seguridad jurídica en la medida en que la norma ha sido materialmente derogada en el momento de emitir sentencia.

Ahora bien, como señala el voto particular, lo que no queda del todo claro no es tanto la adecuación de la medida a la situación que se pretende afrontar como la efectiva justificación de que tal situación genera un caso de extraordinaria y urgente necesidad que valide el uso del decreto-ley en el caso concreto. En este sentido, el magistrado Fernando Valdés Dal-Ré apunta que "[1]a situación del sistema eléctrico, la compleja situación económica y financiera y la lucha contra el déficit tarifario son motivos que narran el contenido de la adopción de la disposición; pero ni justifican la aprobación mediante la promulgación del Real Decreto-ley impugnado, ni explican la razón que 
llevó al Gobierno a tramitar la suspensión del régimen primado de producción de energía eléctrica por medio de esa norma excepcional y no de una ley, excepto en el caso de las instalaciones de producción fotovoltaica". En este sentido, la prudencia respecto a la oportunidad de la medida escogida no debiera convertirse en tolerancia en relación con justificaciones genéricas o incompletas de la urgencia, ya que, en tal caso, el carácter excepcional del decreto-ley queda comprometido y, con ello, la legitimidad democrática de la legislación.

\section{Incidencia de las competencias autonómicas en la ordenación del litoral}

Ya comentamos en su día la STC 87/2012, de 18 de abril, que resolvía una cuestión de inconstitucionalidad en relación con la Ley del Parlamento de Galicia 9/2002, de 30 de diciembre, de ordenación urbanística y protección del medio rural de Galicia, en la que se discutía la aprobación de un deslinde de bienes de dominio público marítimoterrestre en cierto tramo de $\operatorname{costa}^{5}$. La confluencia de competencias autonómicas y estatales en materia de costas ha dado lugar a otros conflictos recientemente, el último de los cuales es el que resuelve la Sentencia 5/2015, de 22 de enero (BOE, núm. 47, de 24 de febrero de 2015), relativa al recurso de inconstitucionalidad promovido por el Presidente del Gobierno contra los artículos 1, 2 y 3 de la Ley de la Comunidad Autónoma de Canarias 7/2009, de 6 de mayo, de modificación del Texto Refundido de las Leyes de Ordenación del Territorio de Canarias y de Espacios Naturales de Canarias sobre declaración y ordenación de áreas urbanas en el litoral canario.

Esta última resolución confirma la jurisprudencia sentada en la STC 87/2012, a la que se remite literalmente para resolver el contencioso en relación con el artículo 1 de la Ley controvertida, por lo que cabe reproducir simplemente lo que el Tribunal Constitucional señala, a saber:

La STC 87/2012, de 18 de abril, FJ 5, establece con meridiana claridad, y se basa para realizar tal afirmación en las SSTC 149/1991, de 4 de julio, y 198/1991 de 17 de octubre, citadas también en este texto, que sólo al Estado corresponde establecer limitaciones y servidumbres sobre los terrenos colindantes al demanio marítimo-terrestre $\mathrm{y}$, entre ellas, la servidumbre de protección, basando su competencia en las facultades que la Constitución reconoce al Estado para establecer una legislación básica en materia de medio ambiente, ex artículo 149.1.23 CE, en conexión con su competencia ex artículo

\footnotetext{
${ }^{5}$ Vid. JARIA I MANZANO, “Jurisprudencia constitucional...”, cit. (2012), p. 12 y ss.
} 
149.1.1 CE para fijar en condiciones de igualdad el ejercicio del derecho de propiedad en todo el territorio, en la medida en que la servidumbre de protección supone una limitación del contenido de la propiedad privada colindante al dominio público marítimo terrestre en aras a garantizar su función social (art. 33 CE). Dicho esto, la doctrina de la STC 87/2012 determina que "las Comunidades Autónomas no pueden establecer disposición alguna al respecto, ni siquiera para reproducir con exactitud las previsiones estatales, operación que quedaría vedada por la doctrina sobre la lex repetita sistematizada por la STC 341/2005, de 21 de diciembre, FJ 9, y cuyo origen último está en la STC 10/1982, de 23 de marzo, FJ 8, según la cual la reproducción de normas estatales en normas autonómicas es inconstitucional cuando la Comunidad Autónoma carece de la correspondiente competencia, salvo que - lo que no es el caso - la reiteración de la norma estatal sea imprescindible para el entendimiento del precepto (STC 47/2004, de 25 de marzo, FJ 8)". $\mathrm{Y}$ esta observación es particularmente relevante en el asunto que cumple resolver, porque va a evitar entrar a la consideración de cuan coincidente sea o no la legislación estatal actualmente vigente, con la legislación autonómica impugnada. Decíamos allí y repetimos en este momento que "la Comunidad Autónoma carece, simple y llanamente, de competencia para adoptar disposición alguna para determinar, ni siquiera por remisión mimética a la legislación estatal, limitaciones o servidumbres sobre los terrenos colindantes con el dominio público marítimo-terrestre dirigidas a su protección y conservación, lo que determina la inconstitucionalidad de la disposición sometida a cuestionamiento. No puede oponerse a esta conclusión, como pretenden la Xunta de Galicia y el Parlamento gallego, que el legislador gallego ha ejercido, al aprobar tal disposición, sus competencias en materia de ordenación del territorio y urbanismo, ya que, tal y como dejó sentado la reiteradamente citada STC 149/1991, estas competencias no pueden incidir en la fijación por el Estado de la servidumbre de protección de costas en ejercicio de competencias que sólo a él corresponden" (STC 87/2012, FJ 5).

Por lo tanto, la aplicación de la doctrina expuesta a la solución del recurso de inconstitucionalidad en este punto, nos lleva a la estimación de los motivos esgrimidos por el recurrente, y ello sin entrar a valorar, porque no resulta necesario, el ajuste constitucional de la disposición transitoria primera de la Ley 2/2013. No teniendo la Comunidad Autónoma de Canarias competencia alguna que justifique la regulación de las limitaciones o servidumbres sobre los terrenos colindantes con el dominio público marítimo-terrestre dirigidas a su protección y conservación, poco importa que la regulación contenida en la Ley canaria impugnada sea o no coincidente en gran medida con la normativa estatal actualmente en vigor, y cuya constitucionalidad no se prejuzga. Sea como sea, la norma autonómica carece de la necesaria cobertura competencial que 
justifique su dictado, en la medida en que las competencias estatutarias en materia de ordenación del litoral no justifican la intervención autonómica en materia de regulación del dominio público marítimo terrestre, o de las servidumbres de protección adyacentes. Por lo expuesto procede declarar inconstitucional y nulo el precepto impugnado [FJ $5 .^{\circ}$ ].

En relación con el artículo 2 de la Ley, el Tribunal Constitucional se remite, asimismo, a su jurisprudencia anterior, en este caso a la STC 46/2007, de 1 de marzo, de acuerdo con la cual "corresponde al Estado definir legislativamente el dominio público estatal y establecer el régimen jurídico de los bienes que lo integran, así como adoptar las medidas precisas para proteger la integridad del demanio, preservar sus características naturales y su libre utilización" (FJ 12. ${ }^{\circ}$ ). Finalmente, en relación con el artículo 3 de la Ley, la exclusividad del Estado respecto al régimen de protección del dominio público marítimo-terrestre y de sus servidumbres acaba también decantando la resolución del Tribunal Constitucional. Hay que decir, en relación con todo ello, como ya dije en su momento, que dicha doctrina no permite integrar adecuadamente la idea de normas adicionales de protección contenida en el artículo 148.9 CE, y cabe criticar la poca disposición del Tribunal a considerar aquí la confluencia de distintos títulos competenciales sobre un mismo espacio físico, lo que, sin embargo, sí que hace en otras ocasiones.

Cabe referirse en este punto a la Sentencia 57/2015, de 18 de marzo (BOE, núm. 98, de 24 de abril de 2015), en la que el Tribunal Constitucional se pronuncia sobre el recurso de inconstitucionalidad interpuesto por más de cincuenta senadores del Grupo Parlamentario Popular del Senado en relación con la Ley del Parlamento de Cantabria 2/2004, de 27 de septiembre, del Plan de Ordenación del Litoral. Dicha norma es objeto de un reproche generalizado en el mencionado recurso, que se refiere a distintas cuestiones respecto a las posibilidades de intervención del Parlamento cántabro en la materia controvertida. De todos modos, las objeciones son más procedimentales que competenciales, lo que delimita el planteamiento y el desarrollo argumental del Tribunal Constitucional. En cualquier caso, a pesar de afectar a la ordenación del litoral, el contencioso se centra en la interfície entre las competencias autonómicas y las municipales, más que entre las estatales y las autonómicas, como era el caso de la sentencia comentada anteriormente.

Para empezar, los recurrentes consideran que, por razón de la materia, la mencionada ley hubiera debido venir precedida de una evaluación de impacto ambiental, a lo que el 
Tribunal Constitucional responde que tal instrumento se limita al procedimiento administrativo, notando además lo siguiente:

Este Tribunal ha sido muy consciente, como ponen de relieve los pasajes de resoluciones ahora reproducidos, del encuadramiento de la evaluación de impacto ambiental en el seno de un procedimiento administrativo y de su consideración como un trámite esencial en un procedimiento complejo de aprobación de obras y proyectos. Ningún sentido tiene apelar a la Directiva 2001/42/CE del Parlamento Europeo y del Consejo de 27 de junio de 2001, para postular que de ella deriva una obligación de insertar en los procedimientos legislativos un estudio específico sobre las consecuencias ambientales de los planes, programas o proyectos objeto de las correspondientes normas, en primer lugar, porque las directivas no pueden utilizarse con carácter general como canon para el enjuiciamiento de la constitucionalidad de las leyes (SSTC 183/2014, de 6 de noviembre, FJ 3, y 147/1996, de 26 de septiembre, FJ 3, entre otras), y, además porque esa directiva fue traspuesta a nuestro derecho interno por la Ley 21/2013, de 9 de diciembre, de evaluación ambiental $\mathrm{y}$, sin necesidad de que nos pronunciemos expresamente en este momento sobre su ámbito de aplicación, es patente que en modo alguno podía haber sido considerada en un procedimiento legislativo ya terminado en la fecha de su promulgación [FJ 4. ${ }^{\circ}$ ].

Tampoco considera el Tribunal Constitucional que el legislador autonómico haya violado la autonomía local constitucionalmente garantizada. En relación con ello, dado que, nuevamente, la objeción de los recurrentes se refiere a la tramitación de la Ley, como en el supuesto mencionado de la evaluación de impacto, el Tribunal Constitucional subraya que no cabe entender que la referida autonomía local genere obligaciones en el marco del proceso legislativo, ya que "[t]ratándose de normas con rango de ley, no puede invocarse el principio de autonomía local para condicionar los correspondientes procedimientos legislativos imponiendo en ellos la audiencia de los ayuntamientos que pudieran resultar afectados por los proyectos en tramitación. Dicho principio actúa como canon de constitucionalidad del contenido de las leyes, no del procedimiento de su elaboración, y desde esta perspectiva se enjuiciarán los preceptos de la ley que se impugna en este recurso" (FJ 5. ${ }^{\circ}$, la cursiva es mía).

Por otro lado, se achaca al texto impugnado no solo la aludida violación de la autonomía local en el procedimiento de aprobación, sino también en relación con los contenidos, particularmente en cuanto a la participación de los entes locales en las llamadas actuaciones integrales estratégicas. En relación con esto, de acuerdo con el Tribunal, “[n]o se trata, por tanto, de valorar en qué medida la participación reconocida 
a las entidades locales en los procedimientos previstos por el legislador autonómico para el desarrollo de las actuaciones integrales estratégicas satisfaga un hipotético 'óptimo constitucional' (STC 47/2005, de 3 de marzo, FJ 10) en cuanto a la intervención municipal en asuntos que conciernan a la comunidad local, sino de examinar hasta qué punto, y a la vista de los intereses supramunicipales concurrentes, el legislador autonómico ha respetado ese mínimo que impone la proclamación constitucional de la autonomía local. Un respeto que, en el juicio global que ahora nos corresponde efectuar, podemos entender satisfecho habida cuenta de que, como ya hemos indicado, en principio, los preceptos controvertidos hacen referencia a la intervención municipal en el desarrollo de las actuaciones integrales estratégicas comprendidas en el anexo III (con la cartografía que figura en el anexo I) de la Ley, respecto de las cuales el legislador autonómico ya ha llevado a cabo una función de delimitación correspondiente a la concurrencia de intereses supramunicipales" (FJ 10. ${ }^{\circ}$.

Posteriormente, el Tribunal Constitucional va desgranando diferentes preceptos impugnados para ir rechazando los reproches de inconstitucionalidad de los recurrentes, centrados, de nuevo, en torno al respeto a la autonomía local y las competencias municipales. En general, el Tribunal Constitucional rechaza las alegaciones contenidas en el recurso, con algunas excepciones. En relación con el artículo 27.1.b de la Ley, se admite su constitucionalidad al entender que el efecto vinculante del informe de la Comisión Regional de Ordenación del Territorio y Urbanismo se limita "a aquellos supuestos en los que se deniegue la concesión de la licencia o autorización por la concurrencia de óbices de relevancia supramunicipal, lo que deja incólumes las potestades municipales para su otorgamiento o denegación en función de criterios estrictamente urbanísticos (esto es, de contraste con el instrumento de planeamiento urbanístico municipal en cada caso aplicable)" (FJ 16.b).

Considera el juez de la constitucionalidad, sin embargo, que el legislador autonómico se ha excedido en la medida en que, en algunos puntos, priva de todo margen a los municipios. Así, en relación con el artículo 45.3 de la Ley, el Tribunal considera que "el legislador autonómico niega todo margen de opción al municipio pues establece que el planeamiento 'dirigirá los crecimientos urbanísticos hacia las zonas con pendientes más suaves'. No cabe vislumbrar en éste precepto presencia alguna de intereses supramunicipales que justifiquen una determinación urbanística que se impone al ayuntamiento por encima de cualquier consideración sobre las características físicas del 
terreno objeto de su actuación. Se ciegan por completo las libertades de crecimiento urbanístico en unos términos tales que niegan la autonomía municipal y conllevan, por tanto, la necesaria declaración de inconstitucionalidad y nulidad del precepto legal" (FJ 17.b).

En cuanto al artículo 51.3, el Tribunal Constitucional llega también a una declaración de inconstitucionalidad, considerando que "[e]n cuanto al art. 51.3, hemos de dar la razón a los recurrentes cuando denuncian que habilita al Ejecutivo autonómico no solo a prescindir de la clasificación urbanística del suelo en el diseño y ejecución de sus políticas sectoriales con incidencia territorial sino incluso a prescindir de las determinaciones aparentemente vinculantes de la propia Ley habilitante. Lo primero supone un debilitamiento del principio de autonomía municipal carente de razón suficiente, lo que representa una quiebra injustificada del principio de autonomía, 'que es uno de los principios estructurales básicos de nuestra Constitución', según dijimos en las SSTC 4/1981, FJ 3; y 214/1989, de 21 de diciembre, FJ 13 c). Lo segundo trastoca el sistema de fuentes y, muy particularmente, el principio de primacía de la Ley, postulado básico de un Estado de Derecho (art. 1.1 CE), como advirtiera este Tribunal en la STC 34/1995, de 6 de febrero, FJ 3. El precepto legal permite que el Ejecutivo autonómico haga uso de esta posibilidad 'para llevar a cabo otras Actuaciones Integrales Estratégicas de carácter turístico, deportivo, cultural o residencial para viviendas sometidas a algún régimen de protección pública', lo que abre la puerta a una amplia panoplia de excepciones a las determinaciones establecidas por el propio legislador" (FJ 18.a).

La última declaración de inconstitucionalidad se produce en relación con la potestad sancionadora de la Administración y hace referencia al apartado segundo de la disposición transitoria octava. En relación con esto, el Alto Tribunal considera lo siguiente:

[L]a previsión del apartado segundo de esta disposición transitoria traslada, en todo caso, a la Administración autonómica el ejercicio de la potestad sancionadora respecto de las infracciones que se cometan en terrenos del área de protección ubicados en municipios cuyo planeamiento no se haya adaptado a la Ley del plan de ordenación del litoral. De modo que la efectividad de esta previsión está sujeta a la condición resolutoria consistente en la efectiva adaptación del planeamiento urbanístico municipal a la Ley recurrida, momento a partir del cual se reintegrará al municipio en el disfrute pleno de sus 
potestades sancionadoras. Estamos, por consiguiente, ante una medida de indudable carácter transitorio pero de discutible naturaleza cautelar. En efecto, según constante doctrina de la Sala de lo Contencioso-Administrativo del Tribunal Supremo, con la posibilidad — reconocida a los órganos competentes para la aprobación inicial de los instrumentos de planeamiento- de suspender la tramitación de otros planes y el otorgamiento de nuevas licencias y autorizaciones de actos que impliquen usos del suelo, se trata de evitar la realización de obras o la aprobación de reglas de ordenación urbanística del suelo que puedan resultar contrarias o incompatibles con el nuevo planeamiento proyectado. En particular, se intenta lograr la efectiva satisfacción de los intereses generales implicados en la actividad administrativa de ordenación urbanística del territorio, intereses cuyo logro podría frustrarse si se llevasen a cabo obras y actividades contrarias o incompatibles con el ya inminente nuevo planeamiento.

Sentado esto, no se acierta a ver qué riesgo para la adaptación del planeamiento urbanístico municipal a la Ley del plan de ordenación del litoral se trata de precaver con la regla contenida en el apartado segundo de la disposición transitoria octava de la Ley recurrida. El precepto traslada por entero al ámbito autonómico el ejercicio de la potestad sancionadora cuando se trate de infracciones cometidas en zonas del área de protección ubicadas en municipios con planes no adaptados a la Ley. De suerte que los municipios quedan enteramente desapoderados para ejercer las potestades que, en materia de disciplina urbanística les reconoce la legislación urbanística general, hasta tanto no lleven a cabo la adaptación de sus instrumentos de planeamiento a las disposiciones de la Ley del plan de ordenación del litoral. Dicho de otro modo, el precepto contiene un acicate o un castigo, si se contempla desde su envés- para que los municipios actúen con presteza y diligencia en la adaptación de su planeamiento a la Ley del plan de ordenación del litoral, pues solo a la conclusión de ese proceso se producirá la reversión íntegra de la potestad sancionadora de la que quedan temporalmente - bien que sin identificación precisa de un término - privados. Con independencia de la efectividad que una previsión de este tipo pueda tener en la consecución del objetivo perseguido (la adaptación del planeamiento municipal a la nueva Ley), lo cierto es que con ella no se evita la aparición de ningún riesgo para la efectividad de las determinaciones de la Ley y representa una privación absoluta del ejercicio de una potestad que la legislación urbanística reconoce a los municipios sin que, por las razones que se acaban de exponer, concurra un interés supramunicipal que lo justifique, por lo que debe declararse su inconstitucionalidad y nulidad [FJ 20. ${ }^{\circ}$.

En último lugar, cabe mencionar un óbiter díctum del Tribunal en el que parece admitir que "la patente desatención por el legislador de ese citado mandato constitucional de 
protección ambiental que contiene el art. 45 de nuestra Carta Magna”, debidamente justificada en un proceso de control de constitucionalidad, podría conducir a la consiguiente declaración de inconstitucionalidad de la norma afectada (FJ 4. ${ }^{\circ}$ ). Si bien es cierto que se trata de una afirmación incidental, no deja de ser una consideración particularmente interesante, dada la tradicional reticencia del Tribunal Constitucional a usar el artículo $45 \mathrm{CE}$ como parámetro de constitucionalidad, lo que debería estimular a los recurrentes en futuros pleitos constitucionales a intentar explorar esta vía y permitir así que vaya definiéndose una línea jurisprudencial a este respecto.

\section{A vueltas con la política hidráulica}

Es sabido y, de hecho, ha sido motivo de comentario habitual en estas páginas el carácter conflictivo que presenta la política hidráulica en España, con un foco de tensión específico relativo a la planificación hidrológica en relación con los trasvases intercuencas. El último episodio constitucional de este largo contencioso, en que se mezclan cuestiones de equilibrio territorial, modelo económico, identidad local y protección del medio ambiente, es la Sentencia 13/2015, de 5 de febrero (BOE, núm. 52, de 2 de marzo de 2015), que resuelve el recurso de inconstitucionalidad promovido por las Cortes de Aragón contra la disposición adicional decimoquinta, disposición transitoria segunda, disposición derogatoria única, apartado tercero, y disposiciones finales segunda, tercera, cuarta y quinta de la Ley 21/2013, de 9 de diciembre, de evaluación ambiental, disposiciones todas ellas que modifican el Plan Hidrológico Nacional y son conexas a ello.

Entiende la institución recurrente que el procedimiento seguido se ha situado al margen de lo previsto por el legislador de aguas, particularmente, el artículo 45.2 del texto refundido de la Ley de Aguas, aprobado por Real Decreto Legislativo 1/2001, de 20 de julio, prescindiendo de los mecanismos establecidos para garantizar la participación autonómica en la planificación hidrológica, por lo que se habría incurrido en un vicio de inconstitucionalidad en relación con los artículos 2, 9.3, 24.1, 137, 149.1.22 CE y artículos 19, 71.8, 17, 21, 22, 23, 72 y 75.3 del Estatuto de Autonomía de Aragón (EAAr). Ante tal despliegue de preceptos presuntamente vulnerados, el Tribunal Constitucional centra el contencioso en tres aspectos: 
Ya ha quedado expuesto que la demanda formula una imputación general al conjunto de preceptos impugnados consistente en la vulneración de numerosos preceptos constitucionales y estatutarios. Sin embargo, tal y como también ha señalado el Abogado del Estado, de las alegaciones de la demanda se desprende con claridad que esa genérica vulneración denunciada aparece mínimamente concretada en relación a tres aspectos que son los que deberemos examinar en la presente Sentencia.

La Letrada de las Cortes de Aragón cuestiona en primer lugar el origen parlamentario de las disposiciones impugnadas, provenientes de enmiendas relacionadas con los acuerdos adoptados en el seno del grupo de trabajo de Memorándum Tajo-Segura, encargado de estudiar diversas cuestiones relativas al régimen jurídico de ese trasvase. De este modo se introducen diversas cuestiones en relación con la transferencia Tajo-Segura, modificándose, asimismo, el régimen jurídico general de las transferencias de agua intercuencas. Todo ello se reputa contrario a la reserva del procedimiento para la aprobación del plan hidrológico nacional que, según la demanda, exigiría la previa elaboración de la iniciativa por el Gobierno; los preceptivos informes del Consejo Nacional del Agua, como órgano de participación de todas las Comunidades Autónomas, y de la Comunidad Autónoma de Aragón, en aplicación de la específica previsión estatutaria del art. 72.3 .

En segundo lugar, específicamente a la disposición final cuarta se le reprocha que modifica el art. 72 del texto refundido de la Ley de aguas, en lo relativo a los contratos de cesión de derechos al uso privativo de aguas que impliquen la utilización de infraestructuras que interconecten territorios de distintos planes hidrológicos de cuenca o, lo que es lo mismo, contratos de cesión de derechos al uso privativo de aguas trasvasadas. La modificación implica, a juicio del Parlamento autonómico, una deslegalización de la materia contraria a los mandatos de la planificación hidrológica que vacía por debajo del mínimo exigible los mandatos constitucionales de protección del demanio hidráulico exigidos por el art. 132 CE.

En tercer y último lugar, a la disposición final quinta se le imputa que menoscaba el régimen de participación en la gestión del agua impuesto por el principio constitucional de colaboración y también vulnera el principio de prioridad de la cuenca cedente, trasunto del principio constitucional de unidad de cuenca, así como la reserva de ley establecida en relación con las condiciones de las transferencias hídricas [FJ 2.․].

En cuanto a las cuestiones procedimentales, el Tribunal Constitucional empieza por notar que la Ley de Aguas no puede "operar como canon de constitucionalidad de la actuación del legislador estatal" (FJ 4. ${ }^{\circ}$ ) —aunque, ciertamente, en ocasiones como, por 
ejemplo, en la STC 30/2011, de 16 de marzo, parecería lo contrario-. También excluye la intervención del Consejo Nacional del Agua en la tramitación legislativa en esta materia (FJ 5. ${ }^{\circ}$ ). Finalmente, el Tribunal Constitucional se pronuncia sobre la omisión del informe preceptivo de la Comunidad Autónoma previsto en el artículo 72.3 EAAr en relación con cualquier propuesta de obra hidráulica o de transferencia de aguas que afecte al territorio de la Comunidad Autónoma. En cuanto a ello, es importante subrayar que, partiendo del carácter vinculante del Estatuto de Autonomía para el legislador estatal, que, por otro lado, lo aprueba como ley orgánica, de acuerdo con el Tribunal Constitucional:

Establecida de esta forma la afectación al territorio autonómico de las transferencias reguladas por los preceptos impugnados y la imposibilidad de una gestión fragmentada de la cuenca, es evidente que dicho trámite de informe preceptivo, exigible sobre cualquier propuesta de transferencia y que tiene por objeto establecer un mecanismo de cooperación en un ámbito en el que resultan afectados intereses estatales y autonómicos, no ha tenido lugar en esta ocasión, por lo que, en principio, contraviene lo previsto en una disposición integrada en el bloque de constitucionalidad (art. 28.1 CE) como es el Estatuto de Autonomía de Aragón, aprobado por Ley Orgánica 5/2007, de 20 de abril, norma institucional básica de la Comunidad Autónoma de Aragón, y que, en cuanto integrante del mencionado bloque, se erige en parámetro de enjuiciamiento de la validez de las disposiciones normativas con valor de ley dictadas por el Estado (al respecto, STC 291/2005, de 10 de noviembre, FJ 8, en cuanto se refiere a la imprescindible acomodación de una norma legal estatal a las disposiciones integrantes del bloque de constitucionalidad).

Por eso hemos de examinar las razones que, según el Abogado del Estado y la Letrada de las Cortes Generales, justificarían tal omisión. El primero de ellos defiende que el precepto debe interpretarse en el marco del art. 19 EAAr, cuyo destinatario son los poderes públicos autonómicos, y como un instrumento de colaboración que no tiene, a diferencia del caso canario, amparo constitucional y no se inserta en el procedimiento estatal. Igualmente aduce que el precepto aplicable no sería el art. 72.3 sino el precedente art. 72.2, relativo a la participación y colaboración de la Comunidad Autónoma en la planificación hidrológica y en los órganos de gestión estatal de los recursos hídricos y de los aprovechamientos hidráulicos que pertenecen a cuencas hidrográficas intercomunitarias que afecten a Aragón. Por su parte, la Letrada de las Cortes Generales considera que la emisión de estos informes debe entenderse referida a la esfera de decisiones de naturaleza ejecutiva o prelegislativa, sin que el procedimiento 
parlamentario de las Cortes Generales pueda quedar condicionado o supeditado a la solicitud de informes a las Comunidades Autónomas.

d) En cuanto a la posibilidad de interpretar el art. 72.3 en relación con el art. 19 EAAr, hemos de señalar que, efectivamente, conforme a la doctrina de la STC 110/2011, el segundo precepto estatutario tiene como destinatario a los poderes públicos aragoneses. En particular, resulta ahora relevante su apartado tercero, según el cual "Corresponde a los poderes públicos aragoneses, en los términos que establece este Estatuto y de acuerdo con el principio de unidad de cuenca, la Constitución, la legislación estatal y la normativa comunitaria aplicables, velar especialmente para evitar transferencias de aguas de las cuencas hidrográficas de las que forma parte la Comunidad Autónoma que afecten a intereses de sostenibilidad, atendiendo a los derechos de las generaciones presentes y futuras."

Sobre dicho apartado hemos declarado (STC 110/2011, FJ 9) que "el precepto solo establece que los poderes públicos aragoneses 'velen' para que no se realicen trasvases entre cuencas que no sean sostenibles, lo que equivale a decir que el precepto no contiene prohibición de los trasvases que pudieran serlo. Pues bien, si se considera, de un lado, que 'velar' no conlleva potestades concretas, sino, como antes indicábamos, meras pautas de orientación, no puede desconocerse que el art. 72.3 EAAr. al atribuir competencias acerca de este extremo a la Comunidad Autónoma, las limita a la emisión de 'un informe preceptivo para cualquier propuesta de obra hidráulica o de transferencia de aguas que afecte a su territorio', técnica esta que, como las de cualquier informe preceptivo pero que no vincule al Estado en la decisión que a éste le corresponde adoptar, hemos reputado que no contradice el reparto constitucional de competencias (SSTC 243/1993, de 15 de julio, FJ 4, y 31/2010, entre otras)".

Siendo esta nuestra doctrina, es claro que ambas previsiones normativas, los arts. $19.3 \mathrm{y}$ 72.3 EAAr, persiguen el mismo objetivo, con independencia de que el destinatario del art. 19.3 no sea el Estado, el cual sí se encuentra evidentemente vinculado por lo dispuesto en el art. 72.3, en tanto que es a quien corresponde la competencia en materia de propuesta de obra hidráulica o de transferencia de aguas a la que se refiere el precepto. Por otra parte, la relación entre los derechos del art. 19 y el informe del art. 72.3 afectaría en todo caso al contenido del mencionado informe, pero no a su necesidad que es lo que aquí discutido.

A estos efectos, es también irrelevante la referencia del Abogado del Estado a que el informe no se inserta en un procedimiento estatal, pues es evidente que la eventual norma estatal que regulase tal procedimiento habría de tener en cuenta lo dispuesto en el 
precepto estatutario en tanto que integrante del bloque de la constitucionalidad en relación con una materia, las aguas, en la que, como soporte físico, coexisten competencias estatales y autonómicas.

No cabe considerar tampoco que el precepto aplicable sea el art. 72.2 EAAr pues, como se desprende de su tenor literal, se refiere a un supuesto, la participación y colaboración en la planificación hidrológica y en los órganos de gestión estatal de los recursos hídricos y de los aprovechamientos hidráulicos que pertenecen a cuencas hidrográficas intercomunitarias que afecten a Aragón, que es distinto de las concretas propuestas en materia de obras hidráulicas y de transferencia de recursos hídricos que pretenda llevar a cabo el Estado.

Por último, no resultan asumibles las razones aducidas por la Letrada de las Cortes Generales, pues supondría tanto como admitir que las Cámaras no quedan concernidas por una norma que ellas mismas han aprobado con el rango de ley orgánica y que, en su condición de norma institucional básica de la Comunidad Autónoma, integra el bloque de constitucionalidad. Tampoco puede entenderse que, precisamente por su carácter preceptivo y no vinculante, entorpezca el procedimiento legislativo o afecte a la autonomía de la Cámara, en la medida en que, por el contrario, puede servir para proporcionar a la Cámara una información adicional a tener en cuenta durante la tramitación legislativa.

De hecho, frente a lo que parece entender la Letrada de las Cortes Generales, el supuesto que venimos examinando presenta evidentes similitudes con el informe o audiencia previos del Parlamento canario establecidos en el art. 45 de la Ley Orgánica 10/1982, de 10 de agosto, de Estatuto de Autonomía de Canarias, en relación con lo establecido en la disposición adicional tercera CE. Así, nuestra doctrina ha examinado supuestos en los que dicho trámite se producía con posterioridad a lo que la Letrada denomina fase prelegislativa, considerando que debía producirse "antes de la convalidación del Real Decreto-ley de que se trata" (STC 35/1984, de 13 marzo, FJ 4, reiterado en la STC 137/2003, de 3 de julio, FJ 9), así como que también resultaba exigible un nuevo informe en el caso de que las enmiendas introducidas en el trámite parlamentario produjeran el efecto de "alterar el proyecto tan radicalmente que no pueda tenerse por informado" [STC 16/2003, de 30 de enero, FJ 9, citada en la STC 164/2013, de 26 de septiembre, FJ 4 e)] e, incluso, que los informes podían solicitarse a petición del Congreso y del Senado (según se expone en la STC 67/2005, de 17 de marzo, FJ 4).

e) En suma, habiéndose omitido el preceptivo trámite de audiencia a la Comunidad Autónoma de Aragón, procede declarar que la disposición adicional decimoquinta, la 
disposición transitoria segunda, la disposición derogatoria única, apartado tercero, y las disposiciones finales segunda y tercera de la Ley 21/2013, de 9 de diciembre, de evaluación ambiental, son contrarias al art. 72.3 EAAr y, por tanto, inconstitucionales y nulas, en los términos que ahora se expondrán [FJ 5.․, la cursiva es mía].

En cuanto a la disposición final cuarta, que modifica el artículo 72 del Texto refundido de la Ley de Aguas, el Tribunal Constitucional considera que, en este caso, no se da contradicción de inconstitucionalidad en la medida en que no existe reserva de ley en materia hidrológica y responde a la competencia en materia de establecimiento del alcance de la demanialidad en materia de aguas continentales del legislador estatal.

En cuanto a la disposición final quinta, el Tribunal Constitucional considera, asimismo, que no existe una contradicción con el bloque de constitucionalidad. En este sentido, el Alto Tribunal afirma lo siguiente:

Así, en cuanto a la infracción del principio de prioridad de cuenca cedente por la fijación reglamentaria de valores mensuales de referencia de los desembalses para satisfacer sus requerimientos propios, es claro que tal fijación en nada altera las determinaciones de la planificación hidrológica que resulten de aplicación, tal como expresamente establece la disposición impugnada, $y$, por otra parte, no se prevé que tales valores se fijen en términos absolutos sino que se permite su adaptación a las circunstancias, dentro del margen predeterminado por la norma. Finalmente procede advertir que nada impide que una vez concretada la habilitación reglamentaria que contiene la norma la Comunidad Autónoma pueda, caso de entender vulneradas sus competencias, plantear la cuestión por la vía procesal procedente.

En cuanto a las atribuciones de la comisión de desembalse, a la que corresponde (art. 33 del texto refundido de la Ley de aguas) "deliberar y formular propuestas al Presidente del organismo sobre el régimen adecuado de llenado y vaciado de los embalses y acuíferos de la cuenca, atendidos los derechos concesionales de los distintos usuarios", tampoco puede ser acogida la pretensión de la demanda, pues la actuación de dicho órgano ha de ajustarse a lo dispuesto en las normas que le resulten de aplicación, sin que, por situarse extramuros de lo debatido en el presente proceso, podamos pronunciarnos sobre la reclamación de participación en la citada Comisión, ya que lo que se pide no está en realidad regulado por la norma que se impugna.

Por otra parte, la queja relacionada con la vulneración del principio de prioridad de la cuenca cedente parte de un entendimiento de los contenidos necesarios del plan hidrológico nacional ex art. 45.1 c), en relación con las transferencias hídricas, que no es 
relevante a efectos constitucionales y que, en todo caso, no se ve contradicho por la disposición impugnada, expresamente sometida en la fijación de los valores de referencia a las determinaciones de la planificación hidrológica. Por lo demás, como señala el Abogado del Estado, este principio de prioridad de la cuenca cedente se ha plasmado en la disposición adicional tercera de la Ley 10/2001, de 5 de julio, del plan hidrológico nacional que solamente permite trasvases cuando el volumen mínimo embalsado en el conjunto de Entrepeñas-Buendía supere los $400 \mathrm{hm}$ [FJ 7. ${ }^{\circ}$ ].

Como conclusión, cabe apuntar que se afirma el valor vinculante para las Cortes Generales de lo contenido en los estatutos de autonomía, que había quedado en entredicho a partir de la STC 31/2010, de 28 de junio, así como la inadecuación de la legislación de aguas en términos de parámetro de constitucionalidad, que, asimismo, parece recomponer la jurisprudencia reciente del Tribunal. En este sentido, más allá del contenido concreto del fallo, la Sentencia comentada parece reconstruir un marco jurisprudencial más razonable en relación con las competencias en materia de aguas sobre el que cabría insistir para reparar la tendencia de los últimos años en este ámbito. Aquí, pues, el Tribunal Constitucional parece apuntar una línea distinta de la criticada en otras resoluciones aquí comentadas, aunque no cabe concebir muchas esperanzas en este sentido vistas las afirmaciones contenidas en otros pronunciamientos aquí analizados. 